\title{
Dextran-Based Nanoparticles to Formulate pH-Responsive Pickering Emulsions: A Fully Degradable Vector at a Day Scale
}

Valentin Maingret $^{\mathrm{a}, \mathrm{b}}$, Clémence Courrégelongue $^{\mathrm{a}, \mathrm{b}}$, Véronique Schmitt $^{\mathrm{a}, *}$, Valérie Héroguez ${ }^{\mathrm{b}, *}$

${ }^{a}$ Centre de Recherche Paul Pascal, UMR 5031 Univ. Bordeaux CNRS, 115 avenue du Dr Albert Schweitzer, 33600 Pessac, France.

${ }^{\mathrm{b}}$ Laboratoire de Chimie des Polymères Organiques, Univ. Bordeaux, CNRS, Bordeaux INP, UMR 5629, Bordeaux, 16 Avenue Pey-Berland, F-33607 Pessac, France.

*corresponding authors

veronique.schmitt@crpp.cnrs.fr

heroguez@enscbp.fr
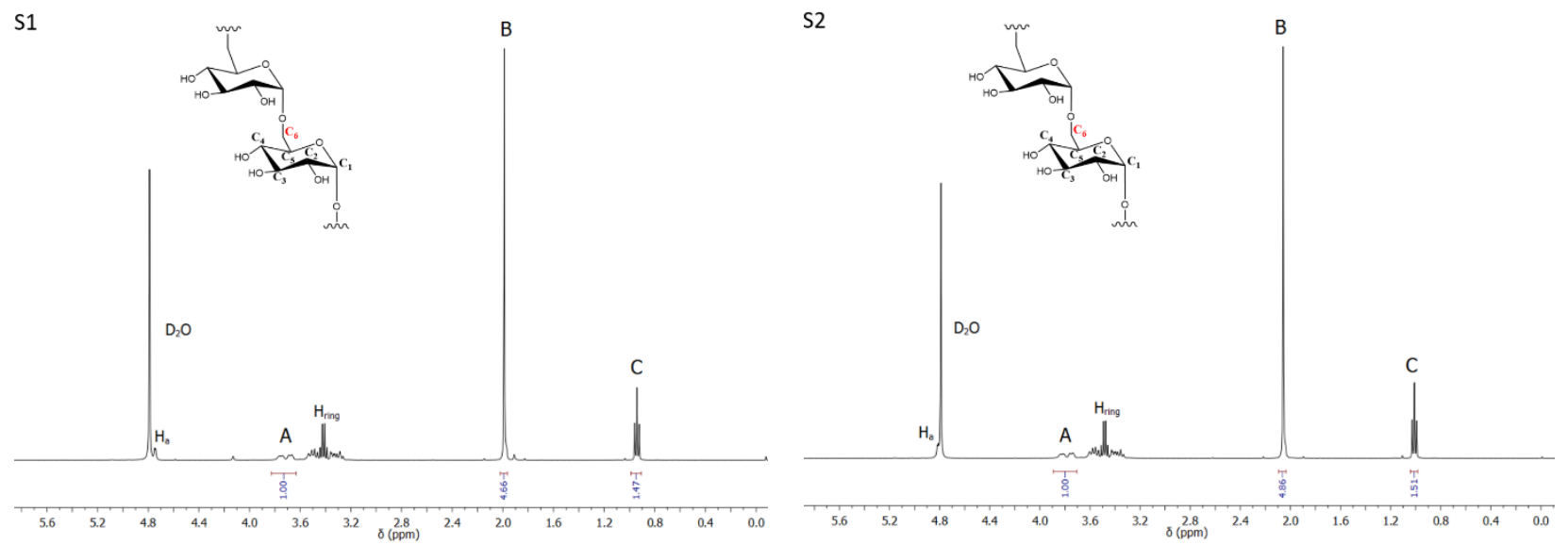

Fig. S1: $400 \mathrm{MHz}{ }^{1} \mathrm{H}$ NMR spectra of Ace-Dextran from S1 and S2 (left and right respectively) after acidic hydrolysis in $\mathrm{D}_{2} \mathrm{SO}_{4} / \mathrm{D}_{2} \mathrm{O}$. Degradation products are Dextran $\left(A, \mathrm{H}_{\mathrm{a}}, \mathrm{H}_{\text {ring }}\right)$, Acetone $(B)$ and Ethanol (C). 


\section{Supporting information S2: ${ }^{1} \mathrm{H}$ NMR analysis to deduce grafting rates}

$\mathrm{H}_{\mathrm{a}}$ signal corresponds to the anomeric proton bonded to $\mathrm{C}_{1}, \mathrm{H}_{\text {ring }}$ signals correspond to hydrogens bonded to $C_{2}, C_{3}, C_{4}$ and $C_{5}$ but none of these were used for calculations.

Dextran $\mathrm{C}_{6}$ hydrogens peaks $\left(\mathrm{A}, \delta=3.9 \mathrm{ppm}, 2 \mathrm{H}\right.$, integration $\equiv 1.00$ ); Acetone $-\mathrm{CH}_{3}$ peaks $(\mathrm{B}, \delta=2.2 \mathrm{ppm}$, $6 \mathrm{H}$ ); Ethanol $-\mathrm{CH}_{3}$ peak ( $\mathrm{C}, \delta=1.1 \mathrm{ppm}, 3 \mathrm{H}$ ). Integrations were normalized for each glucosidic unit to calculate modification rates.

Acyclic modification rate was computed as follows:

$$
r_{\text {acyclic }}=\frac{A_{C} / 3}{A_{A} / 2}
$$

From these, acyclic modification rate was deduced:

$r_{\text {cyclic }}=\frac{A_{B} / 6}{A_{A} / 2}-r_{\text {acyclic }}$

Finally, overall modification rate was computed as follows:

$r_{\text {overall }}=r_{\text {acyclic }}+2 * r_{\text {cyclic }}$

\section{Supporting information S3: Multi angle static light scattering definitions}

The Guinier representation is defined as follows (eq. S4):

$$
\ln \left(\frac{K c}{\Delta R_{\Theta}}\right)=\ln \left(\frac{1}{M_{w}}\left(1+\frac{q^{2} R_{g}^{2}}{3}\right)+2 A_{2} C\right)
$$

where $\mathrm{c}$ is the concentration of the diffusing entity, $\mathrm{M}_{\mathrm{w}}$ its molar mass, $\mathrm{R}_{\mathrm{g}, \mathrm{i}}$ its radius of gyration and $A_{2, z}$ is the second virial coefficient. $K$ is a constant defined by (eq. $S 5$ ):

$$
K=\frac{4 \pi^{2} n_{\text {solvent }}^{2}}{\lambda_{0}^{4} N_{a}}\left(\frac{d n}{d c}\right)^{2}
$$

Where $n_{\text {solvent }}$ is the refractive index of the solvent (water), $\lambda_{0}$ is the laser wavelength, $N_{a}$ is the Avogadro constant and $\mathrm{dn} / \mathrm{dc}$ is the refractive index increment of the diffusive entities (NPs) in the solvent (water).

Whereas $\Delta R_{\theta}$ is calculated at each angle as follows (eq. S6):

$$
\Delta R_{\Theta}=\left(\frac{I_{\text {sample }}-I_{\text {solvent }}}{I_{\text {toluene }}}\right)\left(\frac{n_{\text {solvent }}}{n_{\text {toluene }}}\right)^{2} R_{\Theta}^{\text {toluene }}
$$


where $I_{\text {sample, }} I_{\text {solvent }}$ and $I_{\text {toluene }}$ are the scattered intensities of the sample, the solvent and toluene respectively. $n_{\text {toluene }}$ is the refractive index of the toluene and $R_{\theta}{ }^{\text {toluene }}$ is the Rayleigh constant of toluene at the working wavelength.

The scattering vector $q$ is defined as follows (Eq. S7):

$$
q=\frac{4 \pi n_{\text {sample }}}{\lambda_{0}} \sin \frac{\Theta}{2}
$$

Where $\theta$ is the angle between the incident light and the detector.

\section{Determination of $\mathrm{dn} / \mathrm{dc}$ :}

SEC (Size Exclusion Chromatography) was used to determine the $\mathrm{dn} / \mathrm{dc}$ parameter of the nanoparticles. The $\mathrm{dn} / \mathrm{dc}$ corresponds to the slope of the linear regression of the differential refractive index against the concentration of nanoparticles dispersed in pure water.

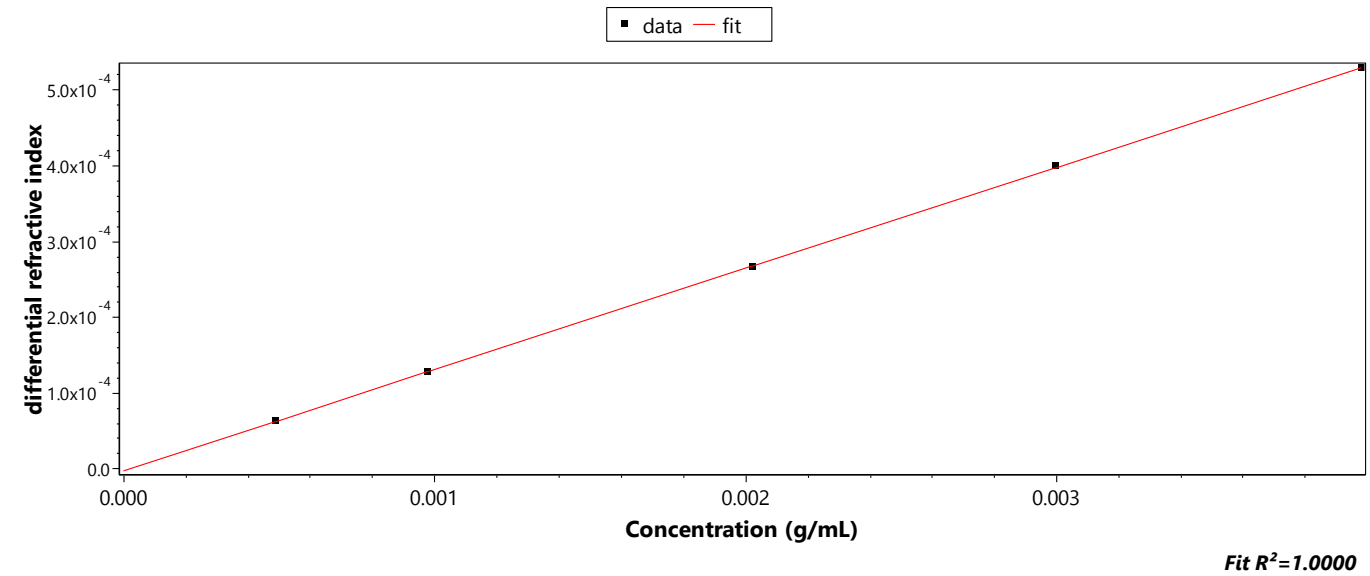

Fig. S4: Determination of $\mathrm{dn} / \mathrm{dc}$ of the NPs with RI measurement at various concentration.

As a result, $d n / d c$ was equal to $0.1337 \pm 0.0005 \mathrm{~mL} / \mathrm{g}$. 


\section{Supporting information S5: Guinier representation}

With the aim to plot the light scattering data by using the Guinier formalism, 6 measurements of $5 \mathrm{~s}$ each were proceeded with an angle step of $5^{\circ}$ from $50^{\circ}$ to $150^{\circ}$ using the ALV instrument. The temperature of the toluene bath was kept to $20^{\circ} \mathrm{C}$. 5 samples with decreasing concentrations were characterized (from $0.08 \mathrm{~g} / \mathrm{L}$ to $0.008 \mathrm{~g} / \mathrm{L}$ ). The data is then analyzed using the ALV stat software, giving the Guinier plot (Fig. S6).

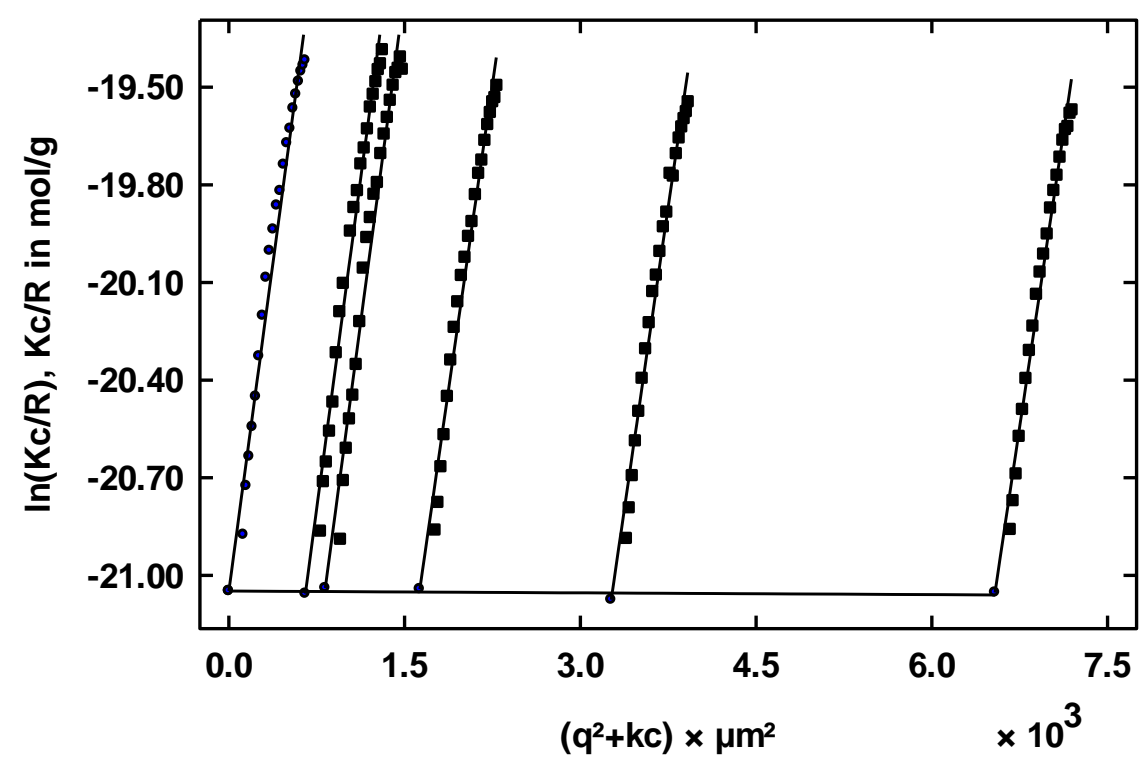

Fig. S6: Static light scattering results represented with a Guinier plot

From this, a double extrapolation (c- $>0 ; q->0$ ) is performed to determine $M_{w}$ and $\left\langle S^{2}\right\rangle_{z}$ (which is the zaverage of the square of the radius of gyration) and finally $R_{g}$. With Guinier assumption, $q^{*} \operatorname{Rg}<<1$, (eq. S4) can be simplified further. The results obtained are summarized in Fig. S7.

\begin{tabular}{ccccc} 
Sample & Conc $/\left(\mathrm{g} / \mathrm{dm}^{3}\right)$ & $\mathrm{M}_{\mathrm{w}}(\mathrm{app}) /(\mathrm{g} / \mathrm{mol})$ & $\left\langle\mathrm{S}^{2}\right\rangle_{\mathrm{z}}(\mathrm{app}) / \mu \mathrm{m}^{2}$ & $\mathrm{R}_{\mathrm{g}}(\mathrm{app}) / \mathrm{nm}$ \\
\hline Conc. $=0$ & 0.0000 & $1.384 \mathrm{e} 9$ & $8.036 \mathrm{e}-3$ & 89.644 \\
\hline $\mathrm{S} 1$ & 0.0764 & $1.390 \mathrm{e} 9$ & $7.250 \mathrm{e}-3$ & 85.144 \\
\hline $\mathrm{S} 2$ & 0.0381 & $1.421 \mathrm{e} 9$ & $7.444 \mathrm{e}-3$ & 86.276 \\
\hline $\mathrm{S} 3$ & 0.0190 & $1.375 \mathrm{e} 9$ & $7.506 \mathrm{e}-3$ & 86.640 \\
\hline S4 & 0.0096 & $1.371 \mathrm{e} 9$ & $8.109 \mathrm{e}-3$ & 90.051 \\
\hline S5 & 0.0076 & $1.395 \mathrm{e} 9$ & $8.102 \mathrm{e}-3$ & 90.012 \\
\hline
\end{tabular}

Fig. S7: Results obtained from the Guinier plot using concentration extrapolation to zero

In the following, $M_{w}$ and $\left\langle S^{2}\right\rangle_{2}$ values used will be $1.38410^{9} \mathrm{~g} / \mathrm{mol}$ and $8.03610^{-3} \mu \mathrm{m}^{2}$ respectively. $M_{w}$ found with q extrapolation to zero was the same. The relative standard deviations calculated by the software for $\mathrm{M}_{\mathrm{w}}$ and $\mathrm{R}_{\mathrm{g}}$ are $1.08 \%$ and $1.9 \%$ respectively. 
$M_{w}$ can be then used to calculate the average polymer density $\rho$ of the NP as described by Dautzenberg in (eq. S8) ${ }^{1}$ :

$$
M_{w}=\frac{4 \pi}{3} \rho N_{a} a_{m}^{3}
$$

Where $a_{m}$ is the geometrical radius of the NP. It is related to the $z$-average of the square of the radius of gyration as follows (eq. S9) ${ }^{1}$ :

$$
\left\langle S^{2}\right\rangle_{z}=\frac{3}{5} a_{m}^{2} e^{-5 \sigma_{a}^{2}}
$$

Where $\sigma_{a}$ is the relative standard deviation of the NPs population. As it is squared, we assume that it is equivalent to the so-called polydispersity index (PDI) derived from the fitting of the autocorrelation function by the cumulants approach which is routinely used in dynamic light scattering (eq. 2). We used the PDI obtained with DLS $90^{\circ}$ (equal to 0.088 at the time of the measurements (Fig. S3)). The standard deviation for PDI was calculated with two measurements and was equal to 0.02 .

Combining (eq. S8) and (eq. S9) allows representing $\rho$ as a function of $\left\langle S^{2}\right\rangle_{z}, M_{w}$ and $\sigma_{a}$ (eq. S10):

$$
\rho=\frac{3 M_{w}}{4 \pi N_{a}} * \frac{1}{\left(\frac{5}{3}\left\langle S^{2}\right\rangle_{z} e^{-5 \sigma_{a}^{2}}\right)^{\frac{3}{2}}}
$$

We finally obtain the following results:

\begin{tabular}{cc}
\hline $\begin{array}{c}\text { Average structural polymer } \\
\text { density } \rho(\mathrm{g} / \mathrm{mL})\end{array}$ & $0.685( \pm 15 \%)$ \\
\hline Geometrical radius $\mathrm{a}_{\mathrm{m}}(\mathrm{nm})$ & $92.87( \pm 5 \%)$ \\
\hline
\end{tabular}

The PDI used for the calculation has a strong influence on the calculated average polymer density. The influence of the standard deviation of $\mathrm{M}_{\mathrm{w}}$ could be then neglected.

\section{Supporting information S9: Surface coverage (C) calculation}

From (eq. 6) the surface coverage can be calculated with the slope of Fig. S10 graph (eq. S11):

$$
C=\frac{1}{4 * \rho_{p} * d_{p} * \text { slope }}
$$


Where $\rho_{p}$ is the particle density $\left(g / \mathrm{m}^{3}\right)$ (here the average polymer density in the nanoparticle) and $d_{p}$ the geometric diameter of the nanoparticles $(186 \mathrm{~nm})$. Slope is here equal to $2.097 \mathrm{~m}^{2} \mathrm{~g}^{-1}\left(2.09710^{-3}\right.$ $\left.\mathrm{mL} . \mu \mathrm{m}^{-1} \mathrm{mg}^{-1}\right)$.

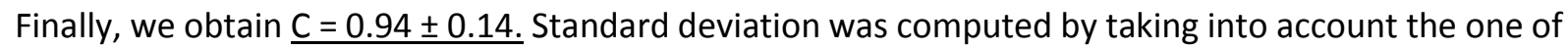
the average polymer density in the nanoparticle.

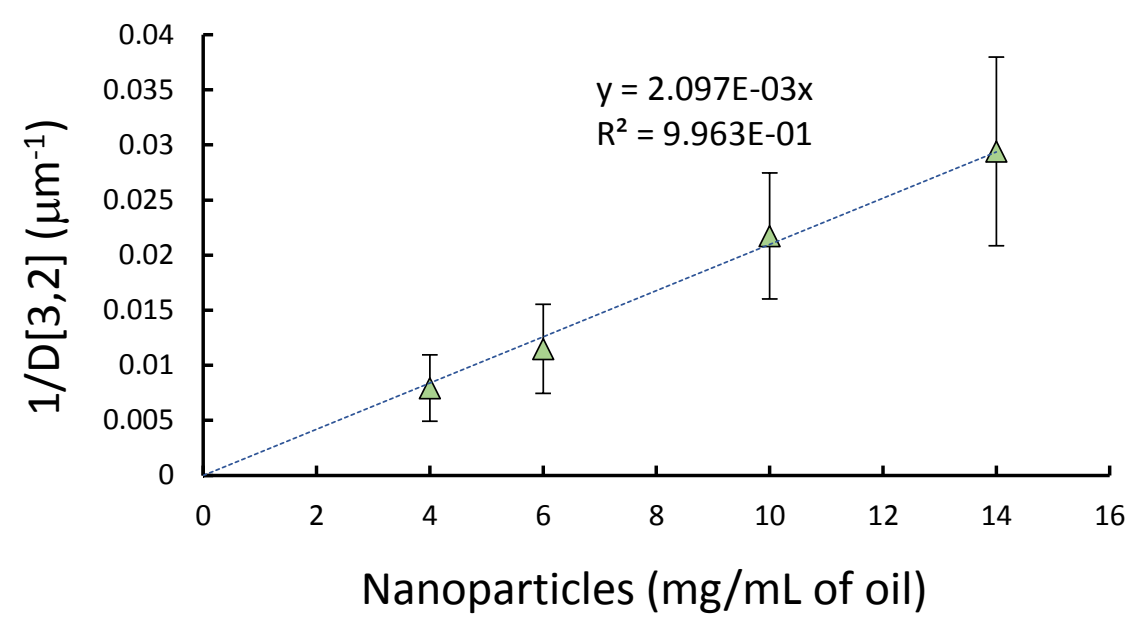

Fig. S10: Limited coalescence domain of dodecane in water droplets stabilized by NPD1 nanoparticles 


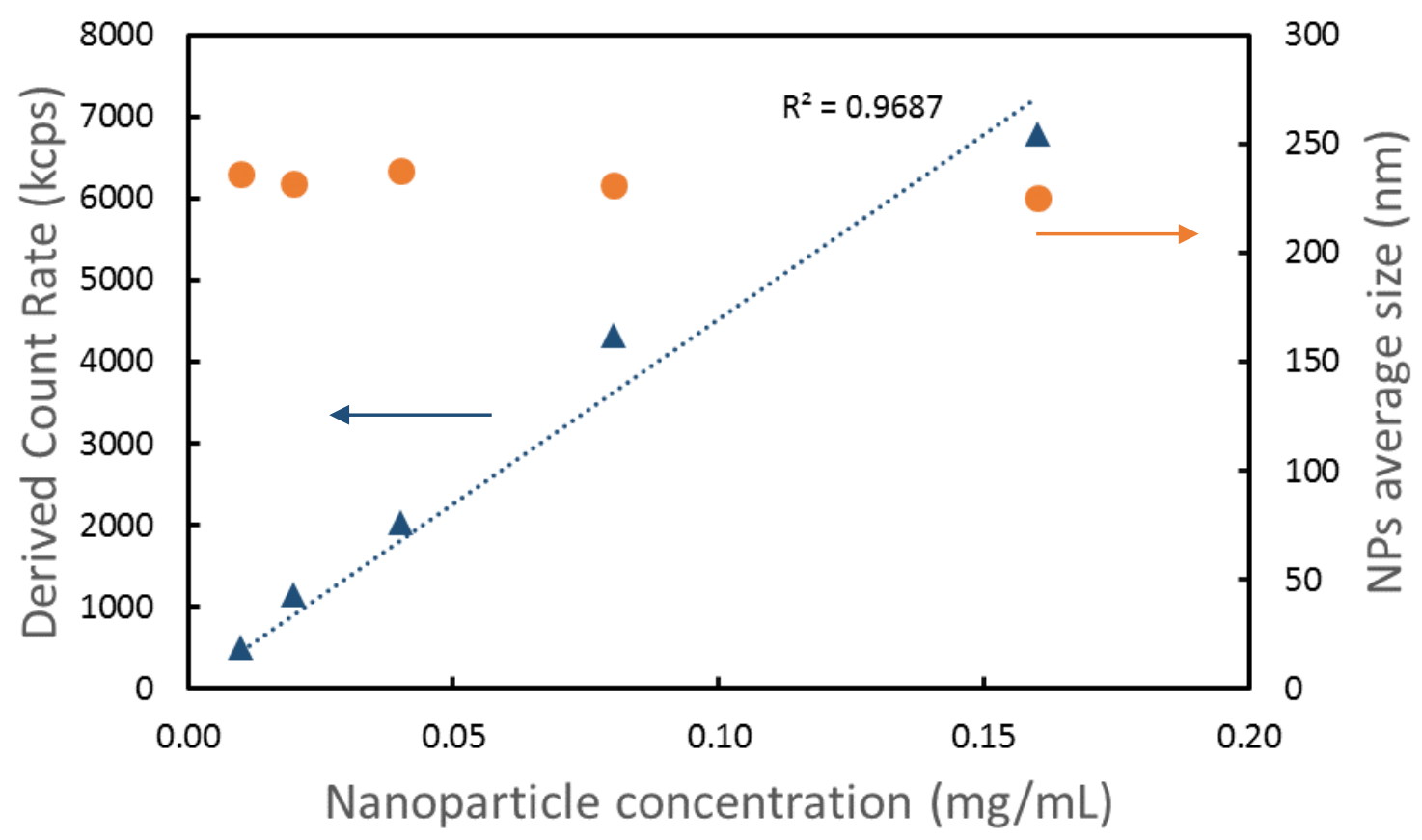

Fig. S11: Calibration curve of DCR with different concentrations of nanoparticles from NPD2 (blue) and their average size obtained by DLS (orange)

There is a satisfying linear relationship between the DCR and the nanoparticle concentration with a small variation of the measured average size by DLS. DCR is linked to the concentration of the nanopartcicles and their radius. Consequently, no variation of the radius means that DCR value only depends on the concentration of nanoparticles.

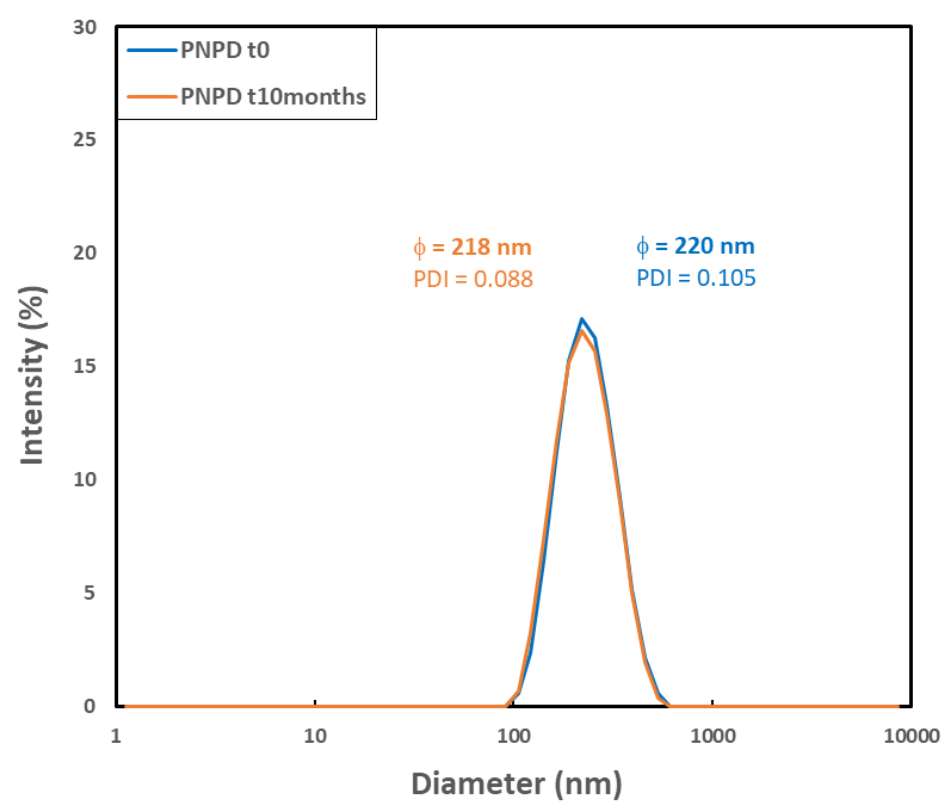

Fig. S12. Size distributions of NPD1 at $t_{0}$ and after 10 months of storage. 


\begin{tabular}{cc}
\hline $\begin{array}{c}\text { Nanoparticles } \\
(\mathrm{mg} / \mathrm{mL} \text { of oil })\end{array}$ & $\mathrm{D}[3,2](\mu \mathrm{m})$ \\
\hline 4 & $126 \pm 50$ \\
\hline 6 & $90 \pm 19$ \\
\hline 10 & $46 \pm 15$ \\
\hline 14 & $34 \pm 14$ \\
\hline 16 & $35 \pm 11$ \\
\hline 18 & $37 \pm 12$ \\
\hline 20 & $30 \pm 6$ \\
\hline
\end{tabular}

Fig. S13: Size measurements of Pickering emulsions stabilized by NPD1 nanoparticles

\section{Reference:}

(1) Dautzenberg, H. Light Scattering Studies on Polyelectrolyte Complexes. Macromol. Symp. 2000, $162(1), 1-22$. 